\title{
吉林-黑龙江高压变质带的确定及意义
}

\author{
周建波*，曹嘉麟，曾维顺，王斌 \\ 吉林大学地球科学学院, 长春 130061 \\ * 联系人, E-mail: zhoujianbo@jlu.edu.cn
}

2013-05-12 收稿, 2013-07-04 接受, 2013-08-07 网络版发表

国家重点基础研究发展计划(2009CB825008, 2013CB429802)和国家自然科学基金(41272241, 41190075)资助

\begin{abstract}
摘要 东北地区佳木斯-兴凯地块的西、南缘发育一弧形展布的高压变质带, 具体包括 佳木斯-兴凯地块西缘增生杂岩带(黑龙江蓝片岩带和张广才-小兴安岭增生杂岩带)和 佳木斯-兴凯地块南缘增生杂岩带(长春-延吉增生杂岩带). 其中, 佳木斯-兴凯地块西 缘增生杂岩带为典型的高压变质带, 形成于晚三叠一早侏罗世 $(210 \sim 180 \mathrm{Ma})$; 而长春一 延吉增生杂岩带以发育高压红窝石片岩为标志, 形成时代为187 230 Ma. 吉黑高压带 形成于太平洋板块三叠纪-早侏罗世的西向俯冲导致佳木斯-兴凯地块自东向西的“剪 刀式”闭合的过程. 该带记录了古亚洲构造域的结束和太平洋俯冲开始的关键时期, 为太平洋板块俯冲启动的标志.
\end{abstract}

\author{
关键词 \\ 吉林-黑龙江高压 \\ 变质带 \\ 黑龙江蓝片岩带 \\ 张广才岭-小兴安岭 \\ 增生杂岩带 \\ 长春-延吉增生杂岩带 \\ 太平洋板块俯冲
}

中亚造山带东缘，沿佳木斯-兴凯地块的西、南 缘发育一弧形展布的高压变质带, 我们称之吉林-黑 龙江高压变质带. 吉黑高压带具体包括佳木斯-兴凯 地块西缘增生杂岩带和佳木斯-兴凯地块南缘增生杂 岩带. 佳木斯-兴凯地块西缘增生杂岩带以黑龙江高 压变质带和小兴安岭-张广才岭增生杂岩带为代表, 其中黑龙江高压变质带以发育蓝片岩等高压变质岩 石为特征, 为由不同时代、不同成因和不同构造背景 的岩石构造混杂而成 ${ }^{[1 ~ 11]}$, 其与张广才岭-小兴安岭 增生杂岩带共同构成了佳木斯-兴凯地块与其西部松 辽地块俯冲拼帖而形成的高压变质带. 佳木斯-兴凯 地块南缘增生杂岩带(长春-延吉增生杂岩带)主体发 育在佳木斯-兴凯地块与华北板块之间. 该带以发育 呼兰群构造混杂岩和延边开山屯混杂岩为代表, 发 育由不同时代，不同性质的岩石混杂而成的增生杂 岩(包括呼兰群、色洛河群、青龙村群和开山屯杂岩 等), 并产出特征性的高压变质矿物组合, 如石头口 门和烟图山等地区发现发育的红帘石片岩组合 ${ }^{[12,13]}$; 开山屯地区增生杂岩的硬绿泥石+纤锰柱石 + 多硅白
云母组合 ${ }^{[14]}$ 等, 它们共同构成了佳木斯-兴凯地块南 缘的特征性增生杂岩带: 长春-延吉增生杂岩带(图 1).

吉黑高压带的提出和进一步研究, 不仅有助于 深人理解东北东部地区的构造演化规律, 同时对深 人探讨古亚洲构造域与环太平洋构造域的转化提供 了事实依据.

\section{1 佳木斯-兴凯地块西缘增生杂岩带的地质 特征与形成时代}

\section{1 西缘增生杂岩带的地质组成}

佳木斯-兴凯地块西缘增生杂岩带由黑龙江高压 蓝片岩带和小兴安岭-张广才岭增生杂岩带两部分组 成, 其中黑龙江高压蓝片岩带(黑龙江杂岩带)主要沿 牡丹江断裂带呈南北向带状分布于佳木斯地体西缘, 主要出露于牡丹江、萝北和依兰等地, 主要组成包括 蓝片岩、绿片岩、大理岩、石英岩和长英质片岩等, 并 混杂有麻山群花岗片麻岩和石墨大理岩等高级变质 岩类. 其中蓝闪石类矿物主要以两种形态出现于

引用格式: 周建波, 曹嘉麟, 曾维顺, 等. 吉林-黑龙江高压变质带的确定及意义. 科学通报, 2013, 58: 2266-2270 Zhou J B, Cao J L, Zeng W S, et al. Confirming of the Jilin-Heilongjiang high-pressure metamorphic belt and its tectonic implications. Chin Sci Bull, 2013, 58: 2266-2270, doi: 10.1360/972013-563 


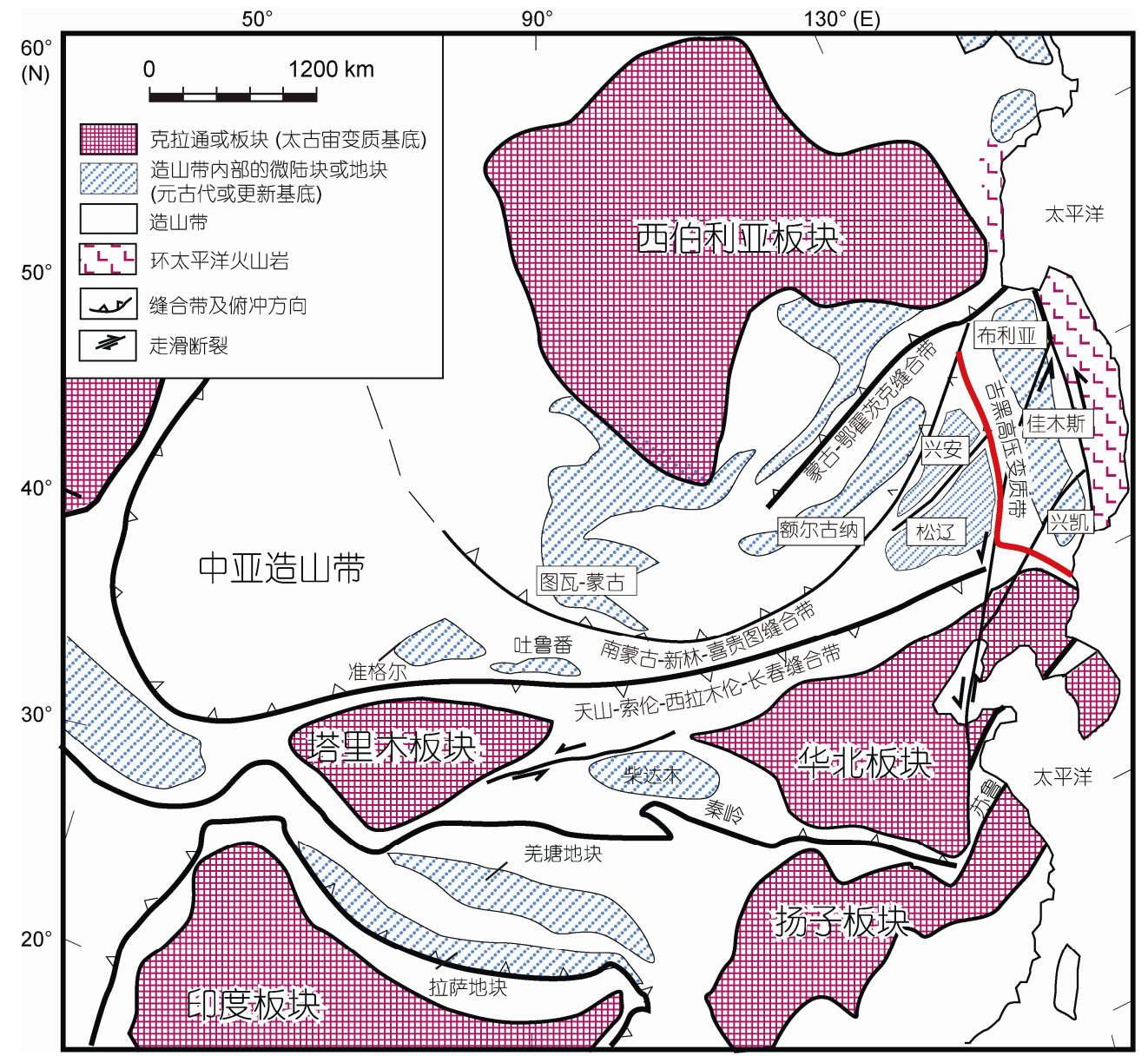

图 1 东北及俄罗斯远东地区构造地质单元划分简图及吉黑高压变质带出露位置(据文献[5,8]修改)

蓝闪绿泥片岩中: 一种是以梳状沿脉壁向中心生长, 另一种是以放射状、束状不定向分布于蓝闪绿泥片岩 中. 电子探针研究表明以蓝闪石为主, 变质温压条件 可达 320 450 ${ }^{\circ} \mathrm{C}, 9 \sim 11 \mathrm{kbar}\left(1 \mathrm{bar}=10^{5} \mathrm{~Pa} \text {, 下同 }\right)^{[8]}$, 显示高压蓝片岩相的变质作用. 小兴安岭-赵广才岭 增生杂岩带组成包括呈构造混杂状分布的早-中古生 代地层和加里东期花岗岩. 其中以小兴安岭地区的 张广才岭群和兴凯地块西缘的黄松群最具有代表性. 这些变质杂岩受到不同程度的挤压剪切作用, 形成 各种糜棱岩或糜棱岩化的岩石, 并遭受低角闪岩相绿片岩相变质作用的改造.

佳木斯-兴凯地块西缘增生杂岩带形成机制与佳 木斯地体向西的俯冲与拼贴密切相关, 张广才岭-小 兴安岭增生杂岩为巨型增生杂岩的主体部分, 而黑 龙江蓝片岩带为地体拼贴过程中仰冲到佳木斯地体 之上的构造混杂岩, 而目前保存下来的黑龙江杂岩
主要为大规模增生楔仰冲到佳木斯地体之上的残留 部分 $^{[8,10 ~ 11]}$.

\section{2 佳木斯-兴凯地块西缘增生杂岩带的形成与 变质时代}

佳木斯-兴凯地块西缘增生杂岩带的原岩与变质 年龄见图 2(a). 佳木斯-兴凯地块西缘与松辽地块的 俯冲增生时代以黑龙江蓝片岩为标志, 目前得到的 28 件锆石 $\mathrm{U}-\mathrm{Pb}$ 年龄确定的黑龙江蓝片岩原岩年龄为 晚二叠到早三叠 (260 210 Ma, 图 2(a)); 而 18 件单 矿物 $\mathrm{Ar}-\mathrm{Ar}$ 年龄限定的黑龙江蓝片岩的变质时代为 210 180 Ma (图 2(a)). 同时, 沿小兴安岭-张广才岭带 分布的增生杂岩也取得了相同的年龄数据，如作者新 近获得的张广才岭群(云母片岩原岩年龄 $250 \pm 2 \mathrm{Ma}$, 变质年龄 $193 \pm 2.4 \mathrm{Ma}$ ), 黄松群(长英质糜棱岩)原岩年 龄 $218 \pm 2 \mathrm{Ma}$, 变质年龄 $200 \pm 7.8 \mathrm{Ma}$ ) 的年代学数据 ${ }^{[5]}$, 


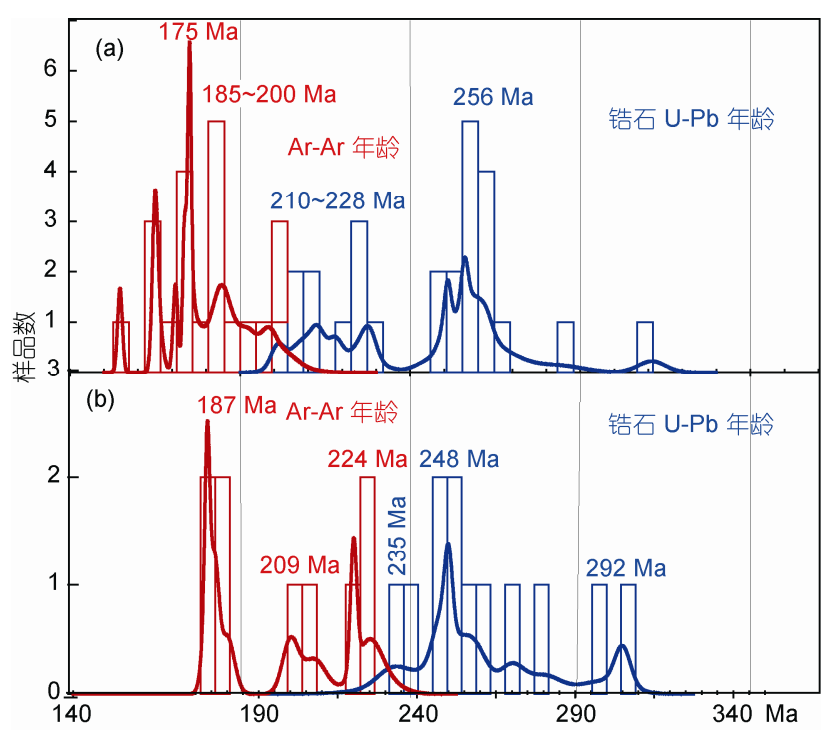

图 2 佳木斯-兴凯地块西缘增生杂岩带(a)和佳木斯-兴凯地 块南缘增生杂岩带的 Ar-Ar, Rb-Sr 和锆石 U-Pb 年龄 (年龄 数据详见文献[5])

这些数据与前人在该区获得的锆石最年轻火山岩的 锆石 U-Pb 谐和年龄 $211 \pm 3 \mathrm{Ma}^{[15]}$ 一致, 共同说明了该 增生杂岩带的形成时代与动力学背景与黑龙江蓝片 岩带相同. 如果考虑到佳木斯-兴凯地块与松辽地块 拼贴过程存在俯冲-增生-折返并仰冲等一系列过程, 且增生杂岩形成顺序为西向东迁移变新的背景. 我 们认为 210 180 Ma 记录了该区增生杂岩的俯冲-增 生-高压变质的峰期事件，而 165 180 Ma 之间年龄 则记录了高压变质的后期折返-仰冲的过程. 因此, 我们认为佳木斯-兴凯地块西缘增生杂岩带的形成时 代为晚三叠-早侏罗世 ${ }^{[5 \sim 11]}$.

\section{2 佳木斯-兴凯地块南缘增生杂岩带}

\section{1 佳木斯-兴凯地块南缘增生杂岩带的地质组成}

佳木斯-兴凯地块南缘增生杂岩带(长春-延吉增 生杂岩带)主要发育在吉林东部地区, 并沿长春、磐 石至延吉一线延伸. 沿断裂带出露的特征性构造-岩 石组合以石头口门-烟图山高压红帘石片岩, 磐石呼 兰群增生杂岩, 色洛河群增生杂岩, 青龙村群增生杂 岩和开山屯增生杂岩等为代表. 其主要特征是: (1) 发育特征性的构造混杂岩. 延边开山屯混杂岩最 早由邵济安等人 ${ }^{[16]}$ 报道, 为一套由滑塌堆积, 浊积 岩以及深海泥质岩一起组成了大陆边缘的增生杂岩.
呼兰群黄莺屯组也有混杂堆积及其蛇绿混杂岩的报 道 ${ }^{[17]}$. 石头口门-烟图山高压红帘石片岩带以发育红 帘石硅质岩为代表, 同时下部有含锰结核的泥岩, 硅 质岩和玄武岩; 中部为细碧-角斑岩和超镁铁质岩岩 块; 上部有硅质岩、杂砂岩、泥岩和生物碎屑灰岩, 也为含蛇绿岩碎块的俯冲增生杂岩 ${ }^{[12]}$. (2) 发育高压 变质矿物组合. 如在石头口门和烟图山等地区发现 发育的红帘石片岩组合 ${ }^{[12]}$; 开山屯地区增生杂岩的 硬绿泥石 + 纤锰柱石 + 多硅白云母组合 ${ }^{[14]}$; 以及呼兰 群含有多硅白云母的蓝晶石片岩带等 ${ }^{[18]}$. (3) 我们最 新的观察显示, 沿该缝合带发育的呼兰群、色洛河群、 青龙村群和开山屯杂岩均不是真正的地层序列, 而 是由不同时代和不同性质的岩石混杂而成，因此我 们认为这些杂岩均为佳木斯-兴凯地块与华北板块之 间俯冲拼贴形成的增生杂岩带 ${ }^{[5]}$.

\section{2 佳木斯-兴凯地块南缘增生杂岩带的形成与 变质时代}

前人针对长春-延吉增生杂岩带的性质曾进行了 大量的研究 ${ }^{[19-22]}$, 关于长春-延吉增生杂岩带的形成 时代, 可以应用近期发表的相关锆石 U-Pb 和单矿物 $\mathrm{Ar}-\mathrm{Ar}$ 进行联合限定. 作为长春-延吉增生杂岩的主 要组成部分, 如呼兰群杂岩、色洛河群杂岩、青龙村 群杂岩和开山屯杂岩, 共 12 件样品的铅石 SHRIMP 或 LA-ICP-MS U-Pb 测定其原岩形成时代分布在二叠 纪至早三叠世 $(234 \pm 4 \sim 287 \pm 6 \mathrm{Ma}$, 图 2(b)), 多数样品 的形成时代为二叠-三叠纪界限附近, 并有大量杂岩 已经属于三叠纪范畴, 因此推测这些增生杂岩主要 形成于早三叠-晚二叠世前后.

长春-延吉增生杂岩带的变质年龄根据近期发表 的变质单矿物 $\mathrm{Ar}-\mathrm{Ar}$ 年龄也得到了较好的制约, 已发 表的吉中地区呼兰群共 9 件变质单矿物的 $\mathrm{Ar}-\mathrm{Ar}$ 年龄 分布区间为 187 230 Ma, 其中峰期年龄分别为 187, 209 和 $224 \mathrm{Ma}$ (图 2(b)), 这些年龄均为采自呼兰群变 质杂岩中的多硅白云母等变质单矿物 ${ }^{[22,23]}$, 应反映 其高压变质的时代. 结合长春-延吉增生杂岩带中红 窝石片岩的原岩年龄为 $239 \pm 11 \mathrm{Ma}^{[13]}$, 由此推测长 春-延吉增生杂岩带的变质年龄区间为 187 230 Ma. 如果进一步考虑到吉黑东部地区广泛发育晚三叠世 磨拉石建造, 如双阳盆地的大酱缸组杂色磨拉石沉 积等 ${ }^{[24]}$, 佳木斯-兴凯地块与华北板块最终拼合时代 可能为早-中三叠纪前后. 


\section{3 问题讨论}

佳木斯-兴凯地块与松辽地块的缝合边界传统上 以黑龙江蓝片岩带为标志, 发育特征性的变质矿物组 合(如蓝闪石, 多硅白云母)等, 代表了高压-低温变质 $320 \sim 450^{\circ} \mathrm{C}, 9 \sim 11 \mathrm{kbar}$, 形成时代为 $210 \sim 180 \mathrm{Ma}^{[5 \sim 8,11]}$, 代表了佳木斯-兴凯地块晚三叠-早侏罗世与松辽地 块的拼贴过程. 然而不可回避的问题是: (1) 作为板 块缝合带的增生杂岩应具有带状连续分布的特征, 而目前观测到的黑龙江蓝片岩只局部分布在上述萝 北、依兰、牡丹江 3 个地区，不具有带状分布的特点; 野外资料表明, 黑龙江蓝片岩为仰冲到佳木斯地块 之上的大规模增生楔的构造残片 ${ }^{[8]}$, 而作为增生楔的 主体部分应产出于佳木斯与松辽地块之间的小兴安 岭-张广才岭缝合带区域; (2) 兴凯地块作为佳木斯兴凯地块的一部分, 由于没有典型的蓝片岩发育, 其 与松辽地块的缝合边界位置至今不清. 导致上述问 题的关键原因是: (1) 传统的研究一直把小兴安岭-张 广才岭杂岩作为松辽地块的组成部分, 而没有将这 些变质杂岩作为板块俯冲增生杂岩来考虑, 事实上 这些岩石的构造组合特征和组成与典型的增生杂岩 可以对比 ${ }^{[5]}$; (2) 本文的地质年龄进一步表明, 以张 广才岭群和黄松群为代表的变质杂岩其形成时代与 变质时代与黑龙江蓝片岩一致, 形成机制与黑龙江 蓝片岩相同, 因此应该作为统一构造单元考虑; (3) 沿张广才岭-小兴安岭分布的巨型同碰撞岩浆带原来 曾定义为加里东期, 近年的年代学研究表明主体形 成于三叠纪前后 ${ }^{[3]}$, 这些巨型岩浆岩带的存在也证明 了该区曾遭受印支期前后佳木斯-兴凯地块向西的俯 冲增生影响. 因此我们认为, 佳木斯-兴凯地块与松 辽地块的板块缝合线由巨型增生杂岩构成, 其中佳 木斯地块西缘的增生杂岩主体由以张广才岭群为代 表的张广才岭-小兴安岭地区前中生代增生杂岩和黑 龙江蓝片岩组成, 而兴凯地块西缘的增生杂岩为以 黄松群为代表的分布在吉林-黑龙江东部地区的前中 生代增生杂岩构成.

佳木斯-兴凯地块与华北板块的缝合边界传统上 也以长春-延吉缝合线为界. 问题的焦点在于, 前人 同时将长春-延吉缝合线作为西拉木伦-长春断裂的 东延部分, 统称为西拉木伦-长春-延吉缝合带. 下述 地质证据将提供两者的区别: (1) 根据岩石圈结构研 究结果 ${ }^{[25]}$, 在西拉木伦-长春一线沿华北板块北缘存
在厚度大于 $130 \mathrm{~km}$ 的岩石圈增厚区域, 可以作为古 亚洲洋板块沿西拉木伦河断裂向南俯冲的有利证据; 但该增厚的区域截止于长春地区，即西拉木伦-长春 缝合带与长春-延吉缝合带的地球物理场明显不同, 显示两者不是同一断裂; (2) 新近的年代学数据显示, 长春-延吉增生杂岩带的原岩形成时代均为二叠纪至 早三叠世 $(234 \pm 4 \sim 287 \pm 6 \mathrm{Ma})$, 而变质时代集中分布 区间为 188 229 Ma，其中变质年龄区间为 220 230 $\mathrm{Ma}$, 即三叠世前后; 其较古生代闭合的西拉木伦-长 春缝合带的缝合时代晚 20 30 Ma; (3) 长春-延吉增 生杂岩与黑龙江蓝片岩的原岩年龄与变质年龄具有 可比性，均为印支期前后发生高压变质作用的产物; (4) 更为重要的原因是, 佳木斯-兴凯地块作为统一 构造单元，其印支期前后的拼贴并不是由于华北与 西伯利亚板块的俯冲, 而是由于太平洋板块的俯冲 所致 ${ }^{[8 \sim 11]}$, 因此, 西拉木伦河-长春断裂作为西伯利 亚与华北板块的缝合带和长春-延吉断裂作为佳木斯 -兴凯地块与华北板块的缝合带不能作为同一构造单 元来考虑. 综合上述分析, 我们认为沿长春-延吉缝 合线发育的增生杂岩与佳木斯-兴凯地块西缘增生杂 岩形成于同一构造背景, 为吉林-黑龙江高压带的重 要组成部分.

\section{4 吉黑高压带的形成动力学背景}

我们定义的吉林-黑龙江高压变质带(简称吉黑 高压带)是指分布在我国东北地区佳木斯-兴凯地块 的西, 南缘呈弧形展布的高压变质带, 具体包括佳木 斯-兴凯地块西缘增生杂岩带(黑龙江蓝片岩带和张 广才-小兴安岭增生杂岩带)和佳木斯-兴凯地块南缘 增生杂岩带. 其中佳木斯-兴凯地块西缘增生杂岩带 形成于晚三叠-早侏罗世(210 180 Ma), 为佳木斯-兴 凯地块向西的俯冲增生而形成的高压变质带; 而佳 木斯-兴凯地块南缘增生杂岩带(长春-延吉增生杂岩 带) 由一系列特征性俯冲-增生杂岩组成, 形成时代为 187 230 Ma. 吉黑高压带的形成时代较西伯利亚与 中国东北地块最终对接的开始时代晚 20 30 Ma, 其 形成演化过程与西伯利亚和华北板块的碰撞无关, 而诱因于太平洋板块的西向俯冲. 吉黑高压带形成 于太平洋板块三叠纪-早侏罗世的西向俯冲导致佳木 斯-兴凯地块自东向西的“剪刀式”闭合的过程. 因此, 吉黑高压记录了古亚洲构造域的结束和太平洋俯冲 开始的关键时期, 为太平洋板块俯冲启动的标志. 


\section{参考文献}

1 李锦轶, 牛宝贵, 宋彪. 长白山北段地壳的形成与演化. 北京: 地质出版社, 1999. 32-50

2 Li J Y. Permian geodynamic setting of Northeast China and adjacent regions: Closure of the Paleo-Asian Ocean and subduction of the Paleo-Pacific Plate. J Asian Earth Sci, 2006, 26: 207-224

3 Wu F Y, Yang J H, Lo C H, et al. Jiamusi Massif in China: A Jurassic accretionary terrane in the western Pacific. Isl Arc, 2007, 16: $156-172$

4 Wu F Y, Zhao G C, Sun D Y, et al. The Hulan Group: Its role in the evolution of the Central Asian Orogenic Belt of NE China. J Asian Earth Sci, 2007, 30: 542-556

5 周建波, 韩杰, Simon A W, 等. 吉林-黑龙江高压变质带的初步厘定：证据和意义. 岩石学报, 2013, 29: 386-398

6 周建波, 张兴洲, Simon A W，等. 黑龙江杂岩的碎屑锆石年代学及其大地构造意义. 岩石学报, 2009, 25: 1924-1936

7 周建波，曾维顺，曹嘉麟，等. 中国东北地区的构造格局与演化：从 $500 \mathrm{Ma}$ 到 $180 \mathrm{Ma}$. 吉林大学学报(地球科学版), 2012, 42: 1234-1246

8 Zhou J B, Wilde S A, Zhang X Z, et al. The onset of Pacific margin accretion in NE China: Evidence from the Heilongjiang high-pressure metamorphic belt. Tectonophysics, 2009, 478: 230-246

9 Zhou J B, Wilde S A, Zhao G C, et al. Was the easternmost segment of the Central Asian Orogenic Belt derived from Gondwana or Siberia: An intriguing dilemma? J Geodyn, 2010, 50: 300-317

10 Zhou J B, Wilde S A, Zhao G C, et al. New SHRIMP U-Pb Zircon ages from the Heilongjiang complex in NE China: Constraints on the Mesozoic evolution of NE China. Am J Sci, 2010, 310: 1024-1053

11 Zhou J B, Wilde S A. The crustal accretion history and tectonic evolution of the NE China segment of the Central Asian Orogenic Belt. Gondwana Res, 2013, 23: 1365-1377

12 唐克东, 郡济安, 李永飞. 松嫩地块及其研究意义. 地学前缘, 2011, 18: 57-65

13 张春艳，张兴洲，夏庆贺．吉林中部硅质岩中锆石 U-Pb 年龄及其地质意义．现代地质, 2009, 23: 256-261

14 吴汉泉, 唐克东, 李存有. 吉林延边开山屯地区蓝片岩相变质作用一一来自硬绿泥石+纤钽柱石 + 多硅白云母组合的证据. 地质通报, 2003, 22: 651-654

15 Wang F, Xu WL, Meng E, et al. Early Paleozoic amalgamation of the Songnen-Zhangguangcai Range and Jiamusi massifs in the eastern segment of the Central Asian Orogenic Belt: Geochronological and geochemical evidence from granitoids and rhyolites. J Asian Earth Sci, 2012, 49: 234-248

16 邵济安, 唐克东, 詹立培. 一个古大陆边缘的再造及其大地构造意义一延边地质研究新进展. 中国科学 B 辑, 1995, 25: 548-555

17 孟繁兴. 吉林中部呼兰群泥质岩递进变质带特征及其地质意义. 吉林地质, 1992, 3: 60-70

18 施性明, 兰玉琦. 吉林省红旗岭呼兰群变质岩系的研究. 长春地质学院院报, 1985, 4: 39-46

19 孙德有, 吴福元, 高山, 等. 吉林中部晚三叠世和早侏罗世两期铝质 $\mathrm{A}$ 型花岗岩的厘定及对吉黑东部构造格局的制约. 地学前缘, 2005, 12: 263-275

20 Cao H H, Xu W L, Pei F P, et al. Zircon U-Pb geochronology and petrogenesis of the Late Paleozoic-Early Mesozoic intrusive rocks in the eastern segment of the northern margin of the North China Block. Lithos, 2013, 170: 191-207

21 Xu W L, Ji W Q, Pei F P, et al. Triassic volcanism in eastern Heilongjiang and Jilin Provinces, NE China: Chronology, geochemistry, and tectonic implications. J Asian Earth Sci, 2009, 34: 392-402

22 Lin W, Faure M, Nomade S, et al. Permian-Triassic amalgamation of Asia: Insights from Northeast China sutures and their place in the final collision of North China and Siberia. Comp Rend Geosci, 2008, 340: 190-201

23 郗爱华, 任洪茂, 张宝福. 吉林中部呼兰群同位素年代学及其地质意义. 吉林大学学报(地球科学版), 2006, 33: 15-18

24 辛玉莲, 任军丽, 彭玉鲸, 等. 中国东北兴蒙-吉黑造山带造山作用结束的标志一一来自晚三叠世磨拉石(大地构造相)的证据. 地质 与资源, 2011, 20: 413-419

25 张兴洲，周建波，迟效国，等. 东北地区晚古生代构造-沉积特征与油气资源. 吉林大学学报(地球科学版), 1998, 38: 719-725 